\title{
Therapeutic Mother Tongue and its Implications on the Work of Polyglot Psychotherapists
}

\author{
Enav Or-Gordon ${ }^{1}$ \\ Charles University
}

\begin{abstract}
Psychodynamic psychotherapy occurs in the lingual field. At its core, the "talking cure" uses the power of words to transform the psyche. Questions arise when the psychologist using language as a central means for therapy is a foreign-language speaker. Research and personal contributions of polyglot therapists in recent years show, that practicing psychotherapy in foreign languages effects the therapist's work on many levels; technical aspects, the therapist's self-perception and role, the therapeutic relationship, therapist's experience and understanding of language as an element in therapy, and more. The present study interviewed nine polyglot therapists in different stages of their career using diverse and different languages in their practice. Analysis of the data in the context of Winnicott's construct of potential space (Winnicott, 1971) and current linguistics theories regarding language embodiment (Pavlenko, 2005) brought about the suggestion of the concept of Therapeutic Mother Tongue, that refers to the language of training. Therapists' experience of Therapeutic Mother Tongue and other languages are explored.
\end{abstract}

\section{Introduction}

The issue of the polyglot therapists working in a few languages has been the focus of some research in recent years. It was shown that working as a therapist in a language other than one's own mother tongue creates technical challenges, and has an effect on psychotherapists' work and the dialogue between therapist and patient on the practical, as well as the dynamic, level. The present study explored aspects of psychodynamic psychotherapy being performed in a foreign tongue, from the perspective of the therapist. Beyond the themes that arose from participants' statements, interpretation of the data suggested the presence of a specific element affecting polyglot therapists' experience of their different languages and their uses in therapy, the element of the language of training to become a therapist. The present article focuses on this particular aspect.

\section{The First Polyglot Psychoanalysts and their Trans-Lingual Psychoanalytic Training}

Most of the forefathers of psychanalysis were polyglots. Freud spoke German, English, French, Spanish, Latin, Italian and Greek, and probably also Hebrew. He did not limit his work to German and at some point in his career had mostly English-speaking patients. Other polyglot psychoanalysts of the first generation include Max Eitingon, Alfred Adler, and Karl Abraham, who spoke 9 languages. Many of the first psychoanalysts were trained in a language that was not their mother tongue (the training language was usually German), and, like Freud, continued to work with their patients in their different languages, using their polyglot skills. Sandor Rado, of Hungarian origin, was analysed by Abraham in German, and continued his professional life in English, in New York. Helen Deutsch, originally from Galicia on the Russian-Polish border,

1 Correspondence concerning this article should be addressed to Enav Or-Gordon; Department of Psychology, Faculty of Education, Charles University, Magdalény Rettigové 4, 11000 Prague, Czech Republic. Email: enavorgordon@gmail.com.

Language and Psychoanalysis, 2021, 10 (1), 4-26.

http://dx.doi.org/10.7565/landp.v10i1.5324 
was analysed by Freud in German, and later emigrated to the United States and continued her work there. Maria Bonaparte's mother tongue was French, however her analysis with Freud took place in German. Margaret Mahler's mother tongue was Hungarian. Her first analysis was in German. She describes her difficulties with English upon immigrating to the United States, as well as criticism from her Hungarian colleagues for speaking with a German, rather than Hungarian accent. In the case of Sandor Ferenczi and Melanie Klein the situation was reversed, when the teaching analyst, Ferenczi, analysed his pupil in a language foreign to him and maternal to her, German (Amati Mehler et al., 1993). A beautiful demonstration of this translingual reality can be found in Ferenczi's Clinical Diary (1932/1985) which he wrote in a language not his mother tongue - German, and in which he moves smoothly between German and English to discuss cases in the original language of analysis. Through Ferenczi's diary it is also possible to get a notion of his sensitivity to the unique effect of words in the original language in which they were used. (This example is also presented in Amati Mehler et al., 1993). In spite of the centrality of language and speech in the psychoanalytic method and the diversity of languages in the reality of the individuals who practiced it, these first analysts did not explore issues of diverse languages used in psychoanalysis. The issue of the language in which one learned to become an analyst, be it mother tongue or foreign language, was also not discussed.

\section{Writings on the Subject of Foreign Language in Psychodynamic Psychotherapy}

Ferenczi was the first of the forefathers of psychoanalysis to write about the function and use of words in a way that is relevant to the question of foreign language and its function in the psyche and in therapy. In his article "On Obscene Words", Ferenczi (1911/1994)describes patients' difficulty in expressing out loud associations in the form of obscene words. He notices that when this difficulty arises, it is connected only to specific, usually common words, and not to foreign versions or more sophisticated (technical) versions of the same concept. Ferenczi traces this difficulty to early developmental stages. Obscene words in their common form are the words at the disposition of the child in the early stage when he is invested in childish sexual theorization. This is also the time when words are experienced more as objects than as abstract ideas and representations. Since these words are strongly connected to sexual fantasy, they are repressed during latency. While the rest of the lingual system develops and takes on an abstract nature, these obscene words remain undeveloped, that is, less abstract and more like objects, and highly charged. As a result, they are ridden with shame and are hard to be thought and pronounced. Foreign words that substitute original obscene words are described by Ferenczi as being used defensively; plainly put, they do not function as obscene words at all.

A few decades later, works began to appear exploring foreign language and the patient. These writers dealt with issues of choice of language in therapy, the effectiveness of therapy in a foreign language, whether early life experiences and trauma can be revealed and processed in a foreign language, the defensive roles of second language and whether these enable or hinder work in therapy, and issues of self-perception in the mother tongue vs. other languages. Although the therapists who wrote these articles were themselves polyglots working in foreign languages as well as their mother tongue, the perspective of the foreign language speaking therapist was for the most part left unexamined (e.g., Krapf, 1935, Buxbaum, 1949, Greenson, 1950).

Exploration of the therapist's perspective can be found in an article by Lagache titled "Sur le Polyglottisme dans l'Analyse" (1956). The author considers different lingual situations that

Language and Psychoanalysis, 2021, 10 (1), 4-26. 
can arise when patient and therapist are both polyglots. These can be a patient working in his mother tongue that is a foreign language for the analyst or vice versa, or when both patient and therapist share the same multiple languages and the patient switches between languages in the process of therapy, and so on. Lagache goes beyond the traditional claim that the patient's mother tongue is the preferable language for therapy, and considers different uses of language in the communication between the patient and therapist in the therapeutic situation. Thus, when a patient's mother tongue is less enabling than a foreign language, the therapist is advised to consider working in a foreign language. On the other hand, when the therapist has the impression that the patient has switched to a second language for defensive reasons, the therapist might choose not to cooperate and not to consider the content expressed in the new language, but stay in the first language used and explore the switch itself. On the countertransference level, Lagache explores the therapist's unconscious motivations for language uses, for example as a means to express his omnipotence. These motivations should be analysed and resolved by the therapist, to avoid acting out through language choice and use. Lagache considers the therapist's languages as useful tools that enable patients to choose a language and move between languages freely. However, the effect of language on the polyglot therapist himself, and therapist's unique relationship with his different languages in the context of psychotherapy and in regard to his professional identity and role, are issues that stay unexplored. Recent decades have seen growing trends of globalization creating new patterns of immigration and diversifying communities. These impact societies and many areas of life. In the context of psychotherapy, cross-lingual encounters become more common. As a result, there is a growing interest in cross-cultural issues in general, and in the field of psychology and psychotherapy. A growing number of researchers and immigrant therapists explore the issue of foreign-language in therapy from their own perspective.

Analysts like Stahl Freedman (2017) Jimanez (2004) and Clauss (1998) describe the experience of working in a few languages and the effect it has on their perception of language's role in therapy, listening to the patient's speech, transference, countertransference and other issues. These writers demonstrate the positive effects that working in more than one language has on the therapist and his role, and the importance and width of the theme of the polyglot therapist. Szekacs-Weisz's chapter "How to Be a Bi-Lingual Psychoanalyst" (2005) presents a fascinating example of the process and challenges faced by the polyglot therapist adjusting professionally to a new language and culture. Szekacs-Weisz is a Hungarian born analyst who immigrated to England in later stages of her career. Working as a therapist in a new language, Szekacs-Weisz realised that different languages are not easily translatable. Since words in the mother tongue are associated with early relationships and experiences, they are not experienced the same as their parallels in a second language.

Beyond the subjective associative system and emotional depth of words in different languages, Szekacs-Weisz also realized that different languages use seemingly identical words in different ways. For example, the Hungarian use of the word Hate is scarce and this word has grave associations, unlike its English parallel that is used in a more casual and lighter manner. The therapist working in a foreign language cannot simply translate his own words or the words of his patient from one language to the other, but needs to learn to work in the new language and to reorient himself in it in a manner unrelated to his mother tongue. Szekacs-Weisz describes another profound change that occurred in her experience as an analyst as a result of her move to a different language. While in Hungarian she feels proficient and has no technical problems in communication, as a therapist in English she finds herself working in a context in which her communication skills are not perfect. This situation has implications not only on her subjective experience as a therapist, but also on the transference, as her native English-speaking patients

Language and Psychoanalysis, 2021, 10 (1), 4-26. 
are inclined to make efforts to understand, and sometimes help the therapist formulate a thought. The experience and role of language in therapy with patients with the same mother tongue is also affected by the polyglot situation. As a therapist who immigrated and changed her major language of therapy, Szekacs-Weisz describes the joy she feels when she has a chance to go back to working with an immigrant patient in Hungarian. One of the challenges in this situation is avoiding the illusion of sameness created by same language and country of origin.

Taking a research approach to the issue of polyglot therapists, Gulina and Dobrolioubova (2018) bring findings from a study exploring experience of foreign therapists that moved to a new country at an earlier stage in their careers, and went through their professional training in English. The researchers found that for polyglot therapists, language had many aspects; vocabulary, cultural background, behavioural differences, meaning, feeling, tonality, symbolism and communication. Language was experienced as connecting and separating between therapist and patient. While some were more attuned to the difficulties created by second language hesitance, less spontaneity and identity issues, others saw the less casual nature of second language, as well as their need to ask more questions in order to understand content and emotional connotations as an opportunity to explore patients' language in a more naïve and open way. A diversity on the topic of preferred language for work was found, with some participants preferring to work in their mother tongue and others preferring their second language.

Costa and Dewaele (2014) compared monolingual and multilingual therapists on their beliefs, attitudes and practice while working with bilingual patients. A sample of 101 therapists showed that multilingual therapists felt more attuned to their multilingual patients and that was not only in cases which they had shared languages. Therapists felt that their own personal experience of learning languages and functioning in foreign languages helped them to be more flexible and more attuned to their foreign-language speaking patients. Other dimensions explored included a shared sense of understanding based on common experiences as immigrants vs. acting on assumptions, freedom of expression while using a foreign language vs. challenges associated with self-expression in a foreign language, and the distance created by not sharing a language vs. closeness when sharing one.

Although the focus of this research was still on the consequences of working with multilingual patients, and not the experience of the multilingual therapists as a theme of its own, the research offers a deep exploration of the inner professional lives of these therapists. An interesting and unexpected theme that emerged was the language of training. In Costa's and Dewaele's sample, multilingual therapists were trained to practice therapy in a language that was not their mother tongue. This was brought up by participants as a factor that effects the way they conduct therapy and even sometimes refrain from conducting therapy in their mother tongue. One participant talked of not considering herself multilingual in the professional sense, because she was only trained to do therapy in one language, English, and had trouble discussing her work in other languages. This Swiss-born therapist living and working in England states:

I wondered whether I wasn't really a fraud, because although I do speak various languages,

I've always been trained in only one, so when I tried to, even when people in Switzerland

Language and Psychoanalysis, 2021, 10 (1), 4-26. 
ask me about the kind of therapy I do, I find it incredibly difficult to explain, because I've

never picked up a French textbook about CBT. (p. 242)

This therapist related to the lack of professional terminology in her mother tongue, French, but her use of the term fraud insinuates that for her, the gap between languages goes beyond the technical level and that deeper issues possibly relating to self-confidence or identity are involved. Another therapist who has noticed the impact of language of training on her work as a therapist is Walsh (2014). Walsh left her homeland England and became an analyst in Israel. She explores her relative freedom and conflict-free functioning as a therapist in Hebrew, in comparison to her difficulties in "going deeper" in explorations with her English-speaking patients. Like Ferenczi, Szekacs-Weisz and others, Walsh describes her first language as more emotionally charged, but as a result also laden with conflicts concerning immigration and the loss of her motherland and tongue. Hebrew is for her lighter and more enabling. Considering these differences, Walsh refers to the fact that she learned to become an analyst in the context of a specific language, Hebrew. She writes that training to become a therapist in this language developed and deepened her Hebrew as a language for psychoanalytic consideration of patients and of herself, while her English remained less emotionally developed. The issue of language of training to become a psychologist surfaced as an important factor in the research presented in this paper. However, before turning to describe these findings and their implications to the question of the polyglot therapist, it would be useful to consider current research regarding polyglots and the place of mother tongue and foreign languages in their cognitive and emotional systems.

\section{Language Embodiment in Polyglots}

Language is a global experience that has aspects beyond the cognitive. Andre Green describes the baby's first encounter with language as sensual: "The infant comes into the world in a bath of language, even if he cannot perceive words during the period of pregnancy while he is in his mother's womb from where he can already hear noises". (2011, p. 20) Didier Anzieu (1985) calls this primary experience associated to language as the Sound Envelope, which is composed of the mother's speech, other surrounding language and sounds, and the sounds coming from the baby's own body. For the baby experiencing the mother's speech language has a cradling, soothing and mirroring effect.

Research from the field of psycholinguistics support this view of language. Pavlenko's theory of Language Embodiment (2005) describes language acquisition as a holistic process. As a child acquires his mother tongue, words are internalised in an embodied manner, since all levels of experience are involved: the cognitive, emotional, sensual and relational. Language is also associated with autobiographic memories and with socialization processes. Neurophysiological evidence supports this theory, showing an involvement of sensory, emotional and also motor neural systems in the processing of language (Kühne \& Gianelli, 2019). Foreign languages are often experienced differently. Words in these languages can be disembodied, lacking in sensual, emotional and autobiographic resonance. As a result, hearing and speaking in these languages might be experienced as detached (Pavlenko, 2012). Some polyglots report feeling less themselves while using a foreign language (Dewaele, 2016). Some also tend to prefer the use of their mother tongue for communication and for inner speech (Dewaele, 2015). Yet research shows that there is no dichotomic difference between mother tongue and other languages. Many factors influence levels of language embodiment, experience and preference,

Language and Psychoanalysis, 2021, 10 (1), 4-26. 
to the extent that sometimes the mother tongue loses its status as the most emotionally experienced or preferable language (Pavlenko, 2005, Dewaele, 2015).

One of these factors is age of acquisition. A foreign language learned at an earlier age tends to be more embodied and feel more natural and emotional to the speaker (Dewaele, 2004). Another factor is the context of language learning. It was shown that personal experience in a given language infuses this language with relevant emotions (Schrauf \& Durazo-Arvizu, 2006). Thus, a language that is learned in the context of a natural environment that offers a variety of experiences tends to be more embodied with speakers feeling more themselves in comparison to a foreign language learned solely in a classroom setting (Pavlenko, 2005, Kramsch \& Gerhards, 2012). Foreign languages are better integrated to the polyglot's sense of self and are more embodied when there is greater personal involvement and motivation in their acquirement (Panicacci \& Dewaele, 2017, Pavlenko, 2005), and when they are experienced in the context of emotional relationships (De Leersnyder, Mesquita \& Kim, 2011, Pavlenko, 2005). For example, foreigners that are highly integrated in the new culture and enjoy more professional and social connections in it feel more themselves while using its language (Hammer, 2016).

Exploring language accessibility and preferences, Grosjean (2015) presented the Complementarity Principle. In polyglots, different languages develop in different contexts and are used for different purposes. Thus, the polyglot's proficiency and preference of use of his different languages is context-dependant. For example, immigrants working in their new country might prefer to use their mother tongue with their close family but feel more comfortable with the local language in a professional context. Bilinguals talking to other bilinguals who share their languages might tend to express themselves in both languages in the same discourse while restrict themselves to one language while speaking to a monolingual (Grosjean, 2013). These findings demonstrate that the experience and place of languages in the psyche of the polyglot individual is complex and dynamic, being shaped and changed by his unique circumstances and linguistic trajectories. The research presented in this paper aims to explore the experience of language in psychotherapy from the perspective of the polyglot therapist working in more than one language. The research question was: What is it like to do therapy in more that one language, and what insights do polyglot therapists have about language, its role and presence in psychotherapy? The current paper focuses on one particular aspect of the finding, which is the unique experience of language of training.

\section{Method}

\section{Participants}

Nine therapists participated in the research. Participants were recruited through professional social media and colleague recommendations. Criteria for participation were that the therapist is a polyglot actively practicing in more than one language. Since most of the literature contributions to the subject of polyglot therapists had English as their non-native language, in the present research an attempt was made to consider other foreign languages. Thus, polyglot therapists who used English as their second language in therapy and have no experience in other foreign languages were excluded. Foreign languages included in the present sample of participants are Italian, Hebrew, Czech, German, French, and Spanish. English was also used by some of the participants, but not as an exclusive foreign language in therapy. A table with participants' information is presented in the appendix.

Ten therapists who expressed interest were approached. One decided not to participate due to time limitations. Five participants were women and four men. Five were immigrants, one was

Language and Psychoanalysis, 2021, 10 (1), 4-26.

http://dx.doi.org/10.7565/landp.v10i1.5324 
temporarily living abroad, and three were living in their homeland. Of these three, one had a minority-group mother tongue and was practicing psychotherapy in a majority language that was for him a second language (an Israeli Arab). Three of the participants were therapists and supervisors, five certified therapists and one in training. All names and identifying details were concealed or changed in reports of the data and findings.

\section{Procedure}

Semi-structured in-depth interviews were conducted. Interviews opened with a request that participates would describe their personal and professional language experiences. Then they were invited to reflect on their experience of the use of language in therapy. The self reflecting, explorative and associatively-guided nature of the interview was influenced by the interviewer's experience as a dynamic clinical psychologist, and familiar to the participants, who were all therapists themselves. When guidance was needed (for example in cases of little self-reflection) it was done in the form of questions and open remarks, gradually from the general to the specific. Interviews lasted between 60 and 90 minutes. They were audio-recorded and transcribed, verbatim including verbal as well as nonverbal data (gestures and sounds, pauses and punctuation, interviewer observations during the interview).

\section{Ethical Issues}

The research was carried out by a doctoral student, the writer of this article, who conducted all interviews and data processing. The researcher was not in direct professional interaction with any of the participants. Participants were made aware of the identity of the researcher, the university and the program to which it was affiliated. Research goals were presented to the participants, as well as information regarding technical issues of data gathering and use. Participants were familiar with the right to see their transcripts and also withdraw from the study at any point. Ethical approval was granted by the university. Confidentiality was kept by changing names and identifying details in data presentation in this article and elsewhere.

\section{Analysis}

Data was initially analysed in the spirit of thematic analysis (Braun \& Clarke 2006). Analysis began as the researcher transcribed the interviews and immersed herself in the data by reading all the texts, familiarizing herself with it in its written form. In the next phase codes were assigned to units of meaning (using colour coding and notes). The approach while coding the data was inductive, exploring content without looking for particular issues based on the researcher's theory or her own personal and professional insights on the subject (Patton, 1990). After several open-coding readings, when no new codes were identified, the different codes were collected into groups of emerging themes and relationships between these themes were considered. Some coded data remained outside the emerging theme system. Keeping these particular data segments in mind and not excluding them brought about the further analysis that is the focus of this article. The fourth stage commenced when all coded extracts were read in the context of their candidate themes, with an attempt to make sure that the candidate themes reflect the original data, and that themes are internally homogenous and distinctive from each other (Patton, 1990). Suggested themes were refined while discussing them with the project supervisor, who was familiar with the initial data. Proceeding to a higher level of analysis, themes were named and arranged in relation to one another creating a system of themes and subthemes (Braun \& Clarke, 2006). A discussion of the findings with a group of colleagues brought about a clearer definition of theme meaning and names. Finally, citations that reflect the essence of each theme and subtheme were selected. A text was created describing the

Language and Psychoanalysis, 2021, 10 (1), 4-26. 
themes, their relationship with each other, relevant literature and connection to the research question.

\section{Thematic Analysis Findings}

Three themes and two subthemes emerged: 1. Polyglot Therapists' Relationship with their Different Languages. 2. Identity. 3. The Polyglot Therapist's Work. Subthemes: 3.1. Technical Issues. 3.2. Non-verbal Elements.

Themes will not be elaborated here, since the focus of the current article is to bring findings and conceptualisations derived from further analysis.

\section{Psychoanalytically-informed data analysis findings: The development of the concept Therapeutic Mother Tongue}

One data segment and the interview dynamics associated with it remained a puzzle even after the thematic analysis was completed. Alina (interviewed in Hebrew) expressed a most intriguing perception of her mother tongue, Russian. She talked of experiencing Russian as loved, rich, artistic and highly enjoyable but at the same time as lacking in unconscious depth. "Russian...is NOT a psychoanalytical language in any way.... There is something with Russian, it is a language of literature, of... anything you want...but psychoanalysis - no".

Understanding this particular statement seemed to require interpretation that would go beyond the thematic level. Further exploration was carried out in the spirit of psychoanalyticallyinformed qualitative analysis (Midgley, 2006). This process yielded the formulation of the concept Therapeutic Mother Tongue, in relation to which all data was further explored. The remainder of this article will describe the reasoning process building up to this formulation, the follow up analysis of data in relation to this concept, and some thoughts regarding its importance in the context of cases of polyglot therapists and our understanding of language in therapy. In order to demonstrate what was unique about Alina's statement, I would start by elaborating on the issue of polyglot therapists' relationship to their different languages.

As was described above, polyglots have different proficiency levels in their different languages and language context, and their languages are differently embodied. Language experience and preferences are influenced by factors such as language history, relationships and motivation. Thus, polyglots tend to have a different relationship with each language. In the context of therapy and the polyglot therapist, Walsh (2014) refers to this complex relationship as Transference to Language:

I suggest that we each possess what may be termed "transference to language" or transference to a state of mind triggered by language. A language, like any other significant object in our lives, will evoke within us a particular set of affective experiences, defences, anxieties, projections, and so forth. (Walsh, 2014, p. 69)

The themes extracted through thematic analysis of the research data reflected the centrality of transference to language, as is reflected in theme no. 1, Polyglot Therapists' Relationship with their Different Languages. The following segment of David's interview demonstrates the rich 
and complex relationships David has with his different languages. David's mother tongue is Hebrew. His father was an immigrant to Israel from Bulgaria, and his maternal grandparents immigrated to Israel from Germany. He studied English at school, and in later years also Arabic. He lived in Germany for a few years in his twenties. Then he immigrated to the Czech Republic, where he married and studied to become a doctor of psychology at the local university. He lives and works in the Czech Republic. Here is how he described his relationship to his different languages: "Hebrew is easy and I love it. English is easy and I love it. But not as Hebrew. If I have to write something, I always choose Hebrew, I have dealt with the question because I started writing something professional - Do I want to write in English straight away so it will be read by English readers, but then I realized it is much easier for me to write in Hebrew so strategically I decided to write in Hebrew. It is the most emotionally close to me. English is a little less close to me but I also love it. Then my third favorite is German, then Arabic and the fifth is Czech... maybe this is why I decided to talk Hebrew to my children right from the start. I love German... My mother would have liked to say that [German was her mother tongue] but it was not...So German is my.... grandmother-tongue. This explains why it was close to me, I heard my mother use it and almost swear in German, this is why I learned it so fast". David's comments about his different languages and their place in his inner world include emotions (about his love for Hebrew and it being most close to him, about Czech being his least favorite), insights regarding the learning process ("this is why I learned it so fast"), associations regarding context that affect his relationship with the language ("My grandmother-tongue"), preferences (prefers to speak to his children in Hebrew) and strategical considerations ("strategically I decided to write in Hebrew").

Other participants also shared comments regarding these different levels of language experience. Alina's statement that was cited above stood out as it was not about her emotional experience of her mother tongue, strategical issues or any of the other aspects, but about the nature of Russian itself, as lacking of psychoanalytic depth and potential. An attempt to interpret this remark in a psychoanalytically-informed manner would require integrating many sources of information: Alina's own statements and understanding, her other comments about language, what is known about Alina's language history and life story, the interview's dynamics, as well as data from other interviews with polyglot therapists and theoretical and cultural information. Considering the dynamics of the interview, Alina kept returning to her statement regarding the nature of the Russian language and seemed bothered by not being able to explain it. As she explored this statement there was some tension in her, that was not felt by the interviewer in other parts of the interview. At some point she stated "...it is very hard, very hard to look for something through the [Russian] language...it is different, there is something...this is it. Here I am stuck".

Alina struggled to find an explanation, and the interviewer found herself engaged while exploring with her. She also found it puzzling that Alina's mother tongue, a language that is complex, rich and produced great and profound works of literature, would be lacking in psychoanalytical depth. She was intrigued by Alina's repeated rejection of possible subjective explanations, that would connect between what she described as the objective nature of Russian and her personal experience of the language. Alina considered her personal history as a source for her impression regarding the Russian language. She grew up in Russia, and spoke only Russian. At the age of 19, right after finishing high school, she immigrated with her family to Israel. Unlike her parents, she and her younger brother made great efforts to master the local Hebrew language. Alina studied music at the university and later on abandoned her plans to become a musician and learned to become a therapist. Alina was certain that the unsuitableness of Russian to psychotherapy is beyond her own experiences as a child in Russian and later as

Language and Psychoanalysis, 2021, 10 (1), 4-26. 
an adult in Hebrew. She also felt the reason was not cultural, that there was something about the language itself making it unfit for use in psychoanalysis, "there is something that is less inclined to the direction [of psychoanalysis [in the language itself".

Analysing the data, we could consider disagreeing with Alina's conviction that her impression is not subjective, and look for differences between the Russian and Israeli cultures. We could also suggest that even though she is not consciously aware of this, Alina's personal experience, for example the style of communication in her family of origin or her experience of maturation in a new country are the cause of her different experiences of Russian and Hebrew. We could also accept Alina's impression that there are some objective innate differences between Russian and Hebrew, making the latter more suitable for psychoanalysis. Indeed, different theories from linguistic relativity to psychoanalysis state that languages embody different world views and self-perceptions (see Jones, 1922, Whorf, 1956, Pavlenko, 2002a, b).

Yet a closer examination of Alina's statements might point us in a different direction. As Alina spoke about Hebrew, she said: "What is the most important is that for me this language Hebrew, is the langue of psychoanalysis". It is interesting to note that again and again, the issue, as well as the perceived difference between Russian and Hebrew centres specifically around these languages' fitness for psychoanalysis. As was mentioned above, Alina became a therapist some years after her immigration to Israel, in Hebrew. Could it be that Alina's experience of the two languages is the result of her encountering psychoanalysis and herself as a therapist first and foremost in the context of Hebrew, not Russian? Acquiring psychotherapeutic skills is a complex process, that involves deep psychic changes. In the process, the therapist-to-be must be involved in intensive professional relationships with his supervisors, go through personal psychotherapy and internalise complex theoretical concepts to make them his own. It is a process of personal change and growth.

If we see the creation of an inner state of a therapist as a developmental process parallel to that of child development, then the supervisor (and other influencing figures such as psychotherapists and teachers) has in that process the role of a parent. Pedder (1986) uses this model, writing about the internalisation of the supervisor: It also echoes Winnicott's (1958) view that "the capacity to be alone is based on the experience of being alone in the presence of someone, (i.e., originally mother) and that without a sufficiency of this experience the capacity to be alone cannot develop" (p. 33). Might we not paraphrase that and say that the capacity to work alone as a therapist is based on the experience of having been alone in the presence of someone (i.e., originally analyst and/or supervisor) and that without a sufficiency of this experience the capacity to work alone cannot develop?

Considering the possibility that Alina's experience of her foreign language as well as her mother tongue was influenced by the training process, it would be interesting to look for signs of such influence in other participants who acquired their skills in a foreign language. George's mother tongue is Arabic, and he is training to become a therapist in Hebrew. The following extract demonstrates how, for him, lingual and professional skills are interconnected: "At the beginning I wanted my own therapist to be a Hebrew speaker, for me to strengthen my language and the emotional language, the emotional Hebrew and the usual Hebrew, I chose and wanted to share with someone my difficulties". A safe environment is an important condition for psychotherapeutic training. Foreign language speakers in the process of training need this safety in order to internalise their foreign language as well. George said: "The supervisors also understood that there is someone here for whom Hebrew is a second language and they helped. They understood that he will see native Hebrew speaking patients and will treat them in his

Language and Psychoanalysis, 2021, 10 (1), 4-26. 
second language. They understood that and gave counselling and guidance and gave tools and helped with articles and methods and you should read this and...until I felt at the first stage that I am with caring people who care for me to grow linguistically and to have confidence and confidence in the language".

Inbal started her internship in Jerusalem a short period after immigrating from Portugal. She expressed similar sentiments, talking of her supervisor's attitude as maternal and accepting: "The supervisor that took me then just...accepted me with all my difficulties and taught me the professional language patiently and lovingly. It was at $\mathrm{H}$. Hospital in one of their clinics in Jerusalem. A lovely place! Today when I am not there, I understand how great it was. Idyllic, even. She used to drive me from [my home town] to work and she helped me a lot". We could say that Inbal and George describe good ego-support provided by an enabling environment. According to Winnicott (1960), this kind of support is what a baby needs in order to develop in the first stages of his life, when it exists in an environment that it has no ego control over. A good enough environment facilitates the appearance of transitional phenomena, that enhance development (Winnicott, 1953). Considering the development of language in infants, Stern (1998) sees language acquisition as happening in the transitional space. The infant who already has ideas of the world (for example, what a teddy-bear is) is presented with a word by the mother (teddy-bear). The infant uses the new word as a transitional object, in a simultaneous act of creating anew and accepting the pre-existing word.

Luciana immigrated from Paraguay to Israel in her forties. Her description of the reincarnation of her name while adopting a new language is reminiscent of this process: "My original last name.... is GeXXXX, not GaXXXX. And when I came here [to Israel], they started calling me GaXXXX. And I invented it. ...I [started to use] GaXXXX. Why? For a few reasons. One, because I thought to myself, this makes sense, here it is closer to Europe and to European immigrants, it makes more sense that my last name that originated from Europe was originally really GaXXXX. And not GeXXXX. It could be that with my grandparent's immigration [from Europe to Paraguay] something changed...Otherwise they would have not called me GaXXXX". Similarly to the baby creating his transitional object that was already there to be created, so to does Luciana invent the name that is given to her by Hebrew speaking others. The story of her grandfather's original name, that she is inventing in order to resolve the gap in pronunciation, is creating a family connection between herself and Hebrew, enabling her to embrace her new name and language. The connection of this potential space (Winnicott, 1971) to Luciana's professional context as a therapist was revealed when she gave the second reason for her adoption/invention of the GaXXXX version of her last name: "and the other thing is like a joke, like a joke I did with myself, to include, if you know from Lacan there is the reason of desire Lacan calls it the little $a$ so I said, let's go for it, I let in the $a$. My $a$ ”.

In George's next comment, we can see the creation of potential space between George and his supervisors, who represent the new (Hebrew) language and therapeutic language. George described how he chose, and thus created, his own therapist, that was recommended to him by his supervisor: "My psychologist I chose by myself, after consulting my supervisor, but the choice and choice of language was mine. I go to a Jewish psychologist in Tel Aviv". As is the case with transitional objects, George is at the same time being given as well as creating his object, his therapist. It seems plausible to conclude, that the language in which a person learns to become a therapist, be it mother tongue or a foreign language, is experienced in a deep way associated with psychotherapy. A therapist can acquire a new language in different stages of his professional development. Using the metaphor of human development to describe the situation of the participants in the current study, we could say that some assimilated a new

Language and Psychoanalysis, 2021, 10 (1), 4-26. http://dx.doi.org/10.7565/landp.v10i1.5324 
language for professional use when they were professionally mature. Others, like Alina, George and Inbal, acquired their foreign language in their professional infant-phase, more or less in parallel to their learning to become psychotherapists. I suggest that for these therapists, this foreign language become embodied in an intense process involving not only the cognitive, but also deep emotional levels, that are a part of the training process and experience. Also, for them, the perception of psychotherapy was intertwined with that same language. This is why, for Alina Hebrew, not Russian, is the language of psychoanalysis. The process described here, with its intensity and wholistic nature, is reminiscent of the process of acquiring a mother tongue (Pavlenko, 2005). I suggest that for polyglot therapists learning to become therapists in a foreign language, the new language becomes their therapeutic mother tongue.

The next section will consider participants' statements regarding language in therapy in light of their mother tongue/therapeutic mother tongue situation.

\section{Diversities in Mother Tongue /Therapeutic Mother Tongue Situations and Their Implications on Psychotherapy in Different Languages}

I shall use the term Psychotherapy Language to refer to a specific language a therapist is actively using in his work. In the case of polyglot therapist, each therapist has two or more psychotherapy languages. Considering three variables, Mother Tongue, Therapeutic Mother Tongue (TMT) and Psychotherapy Language, an array of possible combinations appears. As I shall try to demonstrate later, each combination creates a unique therapeutic situation from the perspective of the therapist. Table 1 presents some of the major combinations of Mother Tongue, TMT and psychotherapy language, and three languages; a, b, c. More possible combinations have been omitted for simplification, as they do not provide additional explanatory relevance:

Table 1. Mother Tongue - Therapeutic Mother Tongue (TMT) - Languages major combinations

\begin{tabular}{l|lll}
\hline \multicolumn{2}{l}{ Mother Tongue } & $\begin{array}{l}\text { Therapeutic Mother } \\
\text { Tongue (TMT) }\end{array}$ & $\begin{array}{l}\text { Psychotherapy } \\
\text { Language }\end{array}$ \\
\hline polyglots & a & a & a \\
& a & a & b \\
& a & b & a \\
& a & b & b \\
& a & b & c \\
\hline polylinguals & a,b & a & b \\
& a & a,b & b \\
\hline
\end{tabular}

Following is a description of these combinations, and some of their implications as expressed by participants in this study.

\section{Polyglots}

Polyglot therapists with same mother tongue and TMT, when treating in their mother tongue (a a a). The classic case of congruency is where mother tongue is also the Therapeutic Mother Tongue and the language in which psychotherapy is conducted. For polyglot psychotherapists in this situation, the adding of another language in some of their therapies enables them to have new insights regarding languages, including their own mother

Language and Psychoanalysis, 2021, 10 (1), 4-26. 
tongue, in psychotherapy. Pavel (mother tongue- Czech, TMT- Czech) is a Czech psychologist who has decided to start accepting patients also in Italian, a language he acquired during a 5 year stay in Italy as a student. Pavel talked of the need to adapt himself while changing from language to language. He realised that when in session with Italian patients, his language and manner are more emotional and spontaneous than in Czech: "At the beginning I had to adjust my language rapidly before starting psychotherapy, and this mainly to adapt to the Czechs. To the Czechs. I had to restrict my emotions...for me it is more spontaneous to be emotional. Sometimes with Italian men it is very emotional". In some cases, the fact that the therapist is usually working in a foreign language, makes opportunities to go back to working in his mother tongue emotionally complicated. Luciana (mother tongue- Spanish, TMT - Spanish) talked of what happens when a Spanish speaking patient in Israel seeks psychotherapy with her because of the fact that she offers psychotherapy in Spanish: "I fail with them from time to time. Because I want to be so OK with them, until I do something and I fail. I do something and the psychotherapy is dropped... It is too close; the transference is too close and then I feel I cannot hold them". The transference can also be affected by the fact that both therapist and patient are immigrants in a foreign land. When asked about transference and countertransference issues while seeing Hungarian patients at the time when she lived and worked in Greece, Edith (mother tongue- Hungarian, TMT - Hungarian, English) responded: "Immediately we start closer because we are one kind, type. It's our secret language that the outside world does not have, right? So, [adds with a smile] we are like magicians and the others are Muggles".

Polyglot therapists with same mother tongue and TMT, when treating in a
foreign language (a a b). These are cases of experienced psychotherapists adding another language to their practise, sometimes in the context of immigration. Edith (mother tongue Hungarian, TMT - Hungarian) added Hebrew to her repertoire, and found herself dealing with technical issues, countertransference, power balance and self-perception as a therapist while working in the foreign language: "Maybe it is because my attachment to Hebrew, maybe it's because I think that I speak Hebrew less good than English, also because, yeah, maybe it is also a power game or kind of...Because that the Hungarian accent is so often ridiculed in Hebrew". Edith added, "I think... [in Hebrew] I more feel that I am like a service provider than like I'm a healer". Luciana has the same mother tongue and Therapeutic Mother Tongue, Spanish. She studied and worked for more than 10 years in Paraguay. Her immigration to Israel meant an encounter with a foreign language both in life and in the psychotherapy room, as she studied Hebrew and started working in Hebrew as a therapist. For Luciana, the local therapeutic perspective itself was also a foreign language. In the clinic where she was asked to repeat her internship, Luciana found a professional discrepancy between her Lacanian Therapeutic Mother Tongue, and the local psychodynamic approach. This meant that Luciana was asked to let go of her Lacanian perspective (language), and adhere to other theoretical points of view: "I had to kill my professional identity and as if...so I pretended... I pretended to be learning new things... and tried to see how should I answer in order to fit...". This discrepancy was later solved when Luciana started working with a local Lacanian supervisor, with whom she could "talk psychotherapy" in Hebrew, and at the same time in her own Lacanian professional language. This process helped her integrate the foreign language into her therapeutic identity.

Polyglot therapists with different mother tongue and TMT, when treating in TMT language $(\boldsymbol{a} \boldsymbol{b} \boldsymbol{b})$. These therapists acquired their skills as psychotherapists in a language other than their mother tongue. They then went on to work in this language. Gulina and Dobrolioubova (2018) interviewed immigrant therapists who became therapists in English and worked in the UK, thus can be defined as having their foreign language English as their Therapeutic Mother Tongue. Like Edith, these participants expressed concerns and anxiety

Language and Psychoanalysis, 2021, 10 (1), 4-26. 
regarding their English, in matters of accent, vocabulary, understanding and communication. Still, most of Gulina and Dobrolioubova's participants perceived English as "an important component of their professional identity" (p.12). Going back to the current study and to Alina (mother tongue- Russian, TMT- Hebrew), we can see a discrepancy between her mother tongue and Therapeutic Mother Tongue. The following sentence demonstrates the importance of Hebrew as the language of therapy to Alina: "My personal psychotherapy, the analysis I undertake for the last 11 years, was in Hebrew. To me, it is a transformative experience". The discrepancy between the two mother tongues can explain Alina's perception of her own mother tongue as not being suitable for analysis, lacking the possibility of finding the unconscious in the discourse. The context of a different mother tongue and Therapeutic Mother Tongue explains Alina's feeling of professional insecurity while working on the premise of her mother tongue: "It is accurate to say that in Hebrew I feel that the professional place fits very well. I have no doubts, no insecurity, nothing of that sort, everything I have - is available". Walsh (2014) suggests, that for therapists who have learned to become therapists in a foreign language, the foreign language continues to evolve. As shall be demonstrated in the next section, the "pre-therapeutic self" present in the mother tongue, might stay "frozen" and less developed in the therapeutic context.

\section{Polyglot therapists with different mother tongue and TMT, when treating in their mother tongue ( $\boldsymbol{a} \boldsymbol{b} \mathbf{a}$ ). For some polyglot therapists, the situation of learning to become a} therapist in a language other than the mother tongue and then treating patients in the mother tongue stresses the gaps between the two mother tongues - the native language and the TMT. Alina said: "With Russian I am like a small child...I like...don't feel professionally secure somehow. Not protected. Not professionally protected". All the psychotherapists who participated in the current research saw patients also in their mother tongue. As mentioned before, some of those who had a Therapeutic Mother Tongue different than their mother tongue felt more comfortable in their second language. Inbal's mother tongue is Portuguese, but since she has undergone almost all the practical parts of her psychotherapy training in Israel, her Therapeutic Mother Tongue is Hebrew: “Today, I can't imagine myself doing psychotherapy in Portuguese, because I learned my whole professional language here, in Hebrew. Even though I studied there". Seeing patients in Portuguese is experienced by Inbal as seeing them in a professional foreign language: "And it was hard for me to ask the questions...in my head, I have the conversations, the intakes, the questions in Hebrew. So, I had to translate and the translation did not sound accurate". Other psychotherapists with different mother tongue and Therapeutic Mother Tongue preferred working in their mother tongue. In the last section of the article, I will bring an extreme example of this preference when I describe the case of David.

\section{Polyglot therapists with different mother tongue and TMT, when treating in another foreign language $(\boldsymbol{a} \boldsymbol{b} \boldsymbol{c})$. This combination represents a situation when one was born to one language, became a therapist in a second language and proceeded to work in a third language. Joel had such a situation. He was born in France and moved with his family to Canada as a child, studied and became a psychologist in Canada. He immigrated to Israel in his twenties, where he learned Hebrew and continued to use it in his work. Joel had more languages in his background, as a child of immigrants from German speaking countries. In his case, the enrichment of his lingual system by a multitude of languages in different life and professional phases created an integrated state he called "... a continuum of mosaic. I am composed from all kinds of parts, experiences, countries... That it is not only a language but also a place and a stage in life". In psychotherapy, as well as in the interview, Joel moves between languages with ease: "when did I feel that I arrived [to fluency]? When I felt free to use other languages. Sounds weird. I mean, if I felt, wait, I have something I would be more}

Language and Psychoanalysis, 2021, 10 (1), 4-26. 
comfortable telling in English, so I told it in English. What do the French say? C'est le ton qui fait la musique. The tonality". It seems that like many of the forefathers of psychoanalysis who were born to one language, learned to work in another and immigrated and continued in yet another language, Joel uses his languages as available tools that are at his disposition according to need. His moving between languages might suggest that for him the lingual system is one whole with different sub-systems that are mutually connected. More than that, in his use of the different languages in the same discourse, he is inviting the patient to explore his own language and use of language from a new perspective.

\section{Polylinguals}

Unlike polyglots, polylinguals, who have acquired two languages as mother tongues have a complex associative system that connects between things, words in one language and words in the other language, so that these languages exist on the same emotional level as one, though differentiated, system (Amati Mehler and co., 1993). The next two sections represent two types of polylinguals.

\section{Polylingual therapists with TMT as one of their mother tongues, treating in his second mother tongue $(\boldsymbol{a}, \boldsymbol{b} \boldsymbol{a} \boldsymbol{b})$. A polylingual therapist learned his Therapeutic Mother} Tongue in one of his native languages, while having at his disposition another native language. This situation seems to enable a natural expansion of the skills and position to both languages. Antonella's mother tongue and Therapeutic Mother Tongue are the same, Italian. She has a second mother tongue, French, that is her father's native language that was also spoken in her childhood home. As a polylingual, she had no trouble adding French to her therapeutic "tool box". French is so natural to her, that she is inclined to continue with it in an automatic way: "When I start speaking French it is automatic and I have problems switching to Italian again". Unlike her polylingual situation regarding Italian and French, English is for Antonella a foreign language she has learned at school. Antonella spoke of having difficulties with adjusting to the use of this language in psychotherapy: "The way I talk of course I don't have the vocabulary of Italian. The way I feel a little bit yes, I am not so confident so I am really careful. It is not automatic; I am more rational than emotional. So lower levels of empathy". It is not only that her vocabulary is poorer in English. As the model of mother tongue vs. foreign language suggests, Antonella's experiences of English is less embodied, thus she finds it harder to be engaged on the emotional level. This does not happen when she moves between Italian and French.

Polyglot therapists with two TMT, treating patients in the TMT that is not the mother tongue ( $\boldsymbol{a} \boldsymbol{a}, \boldsymbol{b} \boldsymbol{b})$. Others might be polylinguals at the level of the Therapeutic Mother Tongue, experiencing their first theoretical readings, supervision and therapies in more than one language. Edith's Therapeutic Mother Tongue is Hungarian, which is also her mother tongue. But English was also used intensively in her training: "It was like that from the beginning. My first patients were in Hungarian. And my training was in Hungarian, but I did professional training in English and, like, somehow it was very natural for me to be in charge and follow a group process in English. And also because of the readings, because of the vocabulary, mmm.... like to me the Hebrew is very much connected to this friends and family situation and English is not". We might say that Edith is a polylingual when it comes to Therapeutic Mother Tongue. Indeed, she is able to move between Hungarian and English professionally with great ease, so that even English is not her mother tongue, she experiences it as such on the therapeutic level. Hebrew is a foreign language for Edith both in general and also on the professional level, as she did not learn psychotherapy in a Hebrew context. Unlike with Hungarian and English, the effect of Hebrew being a foreign language to her is manifested

Language and Psychoanalysis, 2021, 10 (1), 4-26.

http://dx.doi.org/10.7565/landp.v10i1.5324 
in feeling she has much less control over the therapeutic situation: "...maybe I feel more passive yes, and this is why I feel more like a service provider than...maybe this passivity is really important, it's like more......yeah....in general I feel less in control, maybe, when I speak Hebrew [in psychotherapy]”.

\section{Difficulties: When Training Language is not Internalised as a Good Therapeutic Mother Tongue}

Not only developmental processes such as the creation of potential space and internalisation support the perception of training language functioning as a Therapeutic Mother Tongue. Cases of difficulties with language and the development of a professional self also support this perception. David's case represents such a development: David has been working as a therapist for more than 15 years. His mother tongue is Hebrew, but as an immigrant to the Czech Republic, he did all his training in Czech. He described his Czech language skills as good and does not experience major technical obstacles while treating patients in Czech. Given this situation, David's Therapeutic Mother Tongue can clearly be categorized as Czech. That would imply that he would be comfortable working in this language. But immediately after becoming an independent psychologist, and while still living and working in the Czech Republic, David started to work in English and Hebrew, and abandoned Czech. Not fully understanding why he is avoiding Czech in therapy, David said: "I know that I don't treat Czechs as well [as patients in my other languages] ...”

David's difficulties with Czech as a therapeutic language seems to stem from problems in the training process: While learning to become a therapist, David remained alienated from the Czech language. This was apparent in the interview, as he talked of two elements that bothered him with this language. One element was that Czech is the language of his ex-wife and her family, with whom he had a conflicted relationship. He had difficulties accepting their cultural style, mainly when it came to raising children: "let's say that since 1993 [The year when his first daughter was born] I kind of developed an impression of the typical Czech parent, and that impression is not at all positive. And that impression is associated with some typical way of expression, intonation, word use...I guess that at that moment I get locked in this unresolved personal issue, the language in which I lived".

The second element was identified by David during the interview. It had to do with the Czech language's structure, which includes a strong imbedded use of honorific subject pronouns that is distancing for him: "this form of addressing with VY bothers me, yes... This distance makes me feel bad and it does not exist in English [and Hebrew]". David's dislikes the Czech parental style and his experience of access distance due to the language's use of honorifics were barriers in the creation of relationships with supervisors and teachers, that are, as was shown above, developmentally parallel to parent-child relationships. Considering language, it seems that David had problems embracing Czech as a Therapeutic Mother Tongue. This is most evident in his ongoing reluctance to have a Czech supervisor: "What I think is stopping me [from seeking supervision] now is the thought that I would be getting supervision from a Czech professional. And this is not good. There should be no difference. And I did have good experience. But there is some reluctance to go to a local professional".

Having developed in a professionally parentless manner and without establishing a sense of good Therapeutic Mother Tongue, David was left to face the professional context alone. As in many cases of insufficiencies in the mother-child bond, this lack of belonging in its most basic sense apparently had some effect on David's self-esteem as a therapist: "up until 2 years ago I

Language and Psychoanalysis, 2021, 10 (1), 4-26.

http://dx.doi.org/10.7565/landp.v10i1.5324 
had this feeling that I am less capable as a therapist in comparison to Israeli psychotherapists because I did not study in Israel but in The Czech Republic... I just knew that. But two years ago, I got involved in this Israeli web page of discussion about psychotherapy and many people were involved there... It then turned into a secret group...It helped me get free of my insecurity, I could suddenly see, feel, that I have nothing to be ashamed of. That I am OK". Alongside the opportunity to compare himself to other psychotherapists in his own mother tongue, belonging to a secret group in Hebrew had a profound effect on David's identity as a therapist. It seems that this group provided a context that he missed due to insufficiencies in his original relationship with his Therapeutic Mother Tongue. David's case demonstrates that language of training has a crucial role in therapist's development. Its internalisation goes beyond the technicalities of professional vocabulary and proficiency in using it in therapy, to the level of internalisation of the role of a therapist. This, through the creation of meaningful relationships with supervisors, therapists and teachers, and through identification with them and acceptance of their language as one's own Therapeutic Mother Tongue.

\section{Discussion}

The issue of language of training vs. language of practice has gained some professional attention in the last few decades. Studies referring to cultural diversity in training for therapists went from focusing on cultural proficiency and cultural awareness (for example, Maxie, Arnold \& Stephenson, 2006, Dyche \& Zayas, 1995) to exploring language as a distinct feature that needs to be taken into consideration in cross-cultural contexts and specifically in therapy. Research has shown that language poses specific challenges for therapists. Biever et al. (2002) reviewed the literature regarding English-Spanish speaking therapists who have studied in the US and conduct therapy in both languages. They found that all sub-categories of Spanish speakers (Spanish-speaking immigrants, speakers of Spanish mother tongue that were born in the US, speakers of Spanish as a second, heritage language and foreign language Spanish speakers) reported having technical difficulties in the transfer from social to professional proficiency, that is, had trouble working in Spanish after being trained in English. Bilingual therapists also expressed lower levels of self-confidence while working in Spanish. They associated these difficulties to a lack of appropriate professional vocabulary and lack of experience in studying and having supervision in this language.

Castaño, Biever, González and Anderson (2007) addressed experienced bilingual EnglishSpanish speaking therapists who were trained in English. They found that these therapists preferred working in English, even when their mother tongue was Spanish. Participants in the study described attempts they made at improving their functioning as Spanish-speaking therapists by exposing themselves to the language in natural circumstances such as television watching, reading professional literature in Spanish and seeking supervision and peer consultation in Spanish. The writers stress that proficiency is context-dependant and thus it is hard for bilingual therapists to express their knowledge, techniques and understanding of the therapeutic process in a language in which they had no training.

Verdinelli and Biever (2009) also found that amongst experienced bilingual English-Spanish speaking therapists who were totally fluent or reported to have almost no concerns regarding their ability to provide professional service in this language, there was a preference to working in the training language, English. This, in spite of the fact that different sub-categories of Spanish speakers faced different challenges. For example, heritage speakers had more trouble adjusting to different Spanish accents and stressed more the efforts they made to translate from English to Spanish in their minds. Native speakers dealt with recent feelings of isolation. All

Language and Psychoanalysis, 2021, 10 (1), 4-26. 
of the above-mentioned research recommend that more training programs would actively train bilingual therapists in both languages. They all stress the cognitive complexity of the task of conducting therapy, a complexity that is not automatically transferrable from language to language (Biever et al., 2002). These studies focus on the technical and functional needs of therapists-to-be, such as the need for adequate vocabulary and practice in professional thinking in the target language. They point to consequences at the level of language preference, feelings of competence and self-esteem.

Findings presented in this paper support the claim that the language of training is indeed an important factor in the language experience of polyglot therapists. These findings also demonstrate that the training-language's impact goes well beyond the proficiency level and creates an effect at the levels of identity as a therapist and nature of embodiment of the language of training. As was mentioned above, psychotherapists' training process is emotionally intensive, and involves cognitive, professional and personal aspects of the therapist-to-be. Relationships play a crucial role in this process. The supervising relationship is of unique importance, as Freud (1912/1953) writes regarding didactic analysis as part of the training process: "We must not under-estimate the advantage to be derived from the lasting mental contact that is as a rule established between the student and his guide." (p. 116) Using Winnicott's formulations we can say, that when this mental contact is good-enough, a potential space, crucial for growth and development, is created (Winnicott, 1953, 1960, 1971).

This complex experience takes place in the context of a specific language, the language of training and practice. As was demonstrated through participant's comments, in these conditions language itself can function as a transitional object in the service of the therapist's development. As a result, this language's level and nature of embodiment (Pavlenko, 2005) develops and deepens, especially in the context of psychotherapy. In the unique circumstance of learning to be a therapist in a foreign language, psychotherapy and language become intertwined. Walsh (2014) refers to two languages, the psychoanalytic language, and the actual language, which is in her case a foreign language. She writes: "I suggest that the psychoanalytic language becomes integrated, embedded, and expressed within another language, in my case Hebrew" (p.68). As was shown in this article, considering the training-language as a Therapeutic Mother Tongue enables us to understand the experience of different languages, their integration and use, in the polyglot therapist.

\section{Further Thoughts}

Language is one of the most important aspect of psychodynamic psychotherapy. Word choice and associations, dreams and sentence phrasing, make the landscape of the subject's inner world, personal story and the unconscious. Language is also the means for psychological change through interpretation, interventions and the creation of insight (Forrester, 1980). The question of how does a therapist succeed in performing therapy in a foreign language, a language that he knows less well in terms of depth, emotional embodiment and technical knowledge is as relevant in the present days of globalization and immigration, as it was in the days of the forefathers of psychoanalysis (Amati Mehler et al.,1993). The findings presented in this article suggest that the language of training might become the first language of therapy for the therapist. But when this language is foreign, the same questions remain relevant: Beyond the transference to this language, on the practical level, is the therapist speaking a foreign language able to listen and identify the unconscious in the patient's speech through slips of tongue, idiosyncratic speech, words used in a unique way, the verbalization of dreams?

Language and Psychoanalysis, 2021, 10 (1), 4-26. 
Psychoanalysts and psychodynamic therapists exploring these questions come up with interesting and diverse answers. For example, Chilean psychoanalyst Jimanez (2004), who lived and worked for five years in Germany, came to the conclusion that the basic patienttherapist contact is trans linguistic, and is based on affective attunement. Jimanez describes many moments of lingual uncertainty, when he was failing to fully understand his patient's verbalisation, or had trouble producing accurate interventions. Jimanez realised, that when he allowed himself to listen applying psychoanalysis' fundamental law, without an effort to decipher each word verbally, he was able act as the "translator of the unconscious" (p. 1375) and was able to offer meaningful interpretations. His patients then tended to rephrase his unpolished verbalisations, thus making the interpretations more accurate, and much more their own. Jimanez (2004) also suggests, that his recent acquisition of the German language made him more alert to literal meanings overlooked by native speakers. Gulina and Dobrolioubova (2018) bring similar findings, suggesting that polyglot therapists sometimes find themselves more alert to unique verbalisation, slips of tongue and double meaning in a foreign language.

Stahl Freedman (2017) discusses the common assumption that the more the therapist and patient are similar in background and language, the better the patient will be understood. In her view, this approach only intensifies an illusion of familiarity in both patient and therapist. Instead of assuming to know the patient's language and inner world, Stahl Freedman suggests the therapist should maintain a position of curiosity and of not knowing. He should focus on learning the patient's personal language, as "every analysis is a cross-cultural treatment" (p. 95). It might be suggested, that as polyglots have the advantage of listening to language from within as well as from without, they are more inclined to pick up the unconscious elements in their patients' verbalisation. On the other hand, when proficiency and knowledge of the language and its cultural depth are less than perfect, some nuances might be missed.

The present article cannot contribute directly to the discussion regarding the ability of foreign therapists to hear the unconscious. But it can offer a new perspective on the question itself. Of the many writers who addressed the issue, none has singled out the case of the foreign language being a Therapeutic Mother Tongue (an exception is the fascinating article by Walsh, 2014, that was quoted above). Does learning to become a therapist in a foreign language create a unique attunement to the unconscious, less accessible to native speakers, or is the therapist less able to identify the unconscious, while he is himself in a less known lingual environment? And are there differences between the use of the foreign Therapeutic Mother Tongue and any other foreign language? Further research regarding the use of mother tongue, a foreign Therapeutic Mother Tongue and foreign language in therapy might shed some more light on these questions and on the issue of listening to the unconscious in therapy in general. The current findings are a result of a specific sample of participants, their life experiences and unique personalities. Regarding the interviewer, all interviews were conducted in languages she actively uses for research and therapy, but some were conducted in her mother tongue while others in languages acquired in later stages of her life. The same as with therapists working in diverse languages, this diversity might have affected data gathering in levels of proficiency, interaction and interview management. Since results of in-depth, qualitative methods rely heavily on the lingual information gathered through interviews, another sample of participants and interviewer might have resulted in different findings.

Beyond this general limitation structured in most qualitative research protocols, there is one source of inconsistency that might have affected results. At the beginning phases of the research, we did not expect to address language of training as a significant variable. Interviews were conducted in one of the participant's active therapeutic languages, without it being Language and Psychoanalysis, 2021, 10 (1), 4-26. 
necessarily their mother tongue or language of training. For example, Pavel was interviewed in Czech which is his mother tongue and his language of training. David was interviewed in Hebrew which is his mother tongue but not his language of training. George was interviewed in Hebrew which is his language of training but not his mother tongue. And Antonella was interviewed in English, a language in which she works but is neither her mother tongue nor her language or training. Further research regarding Therapeutic Mother Tongue should design data gathering while considering the issue of language of interview and its status for the participant.

Dewaele (2015) explored a specific manifestation of language embodiment that he termed "the language of the heart". He was interested in polyglots' use of their different language in inner speech and in emotional inner speech, language manifestations that are highly personal and intimate. Polyglots tend to use their mother tongue as the main language of inner speech. However, Dewaele found that foreign language was likely to become more intimate when subjects experienced themselves as more proficient, used it more and had a strong social use of it. The context of acquisition and perceived emotionality of the foreign language also affect language's tendency to become a language of the heart. In cases of particular emotional connotation between a foreign language and the emotional experience, the same language might be preferred for inner speech regarding this context.

Inner speech and emotional inner speech are aspects of language highly relevant to the work of the psychotherapist, who is trained to constantly engage in inner speech as a tool for keeping track of his internal processes, and processing the patient's discourse. Participants in the current research were not asked about their use of inner speech in therapy. It would be intriguing to see further research addressing this particular question. The case of polyglot therapists presents a unique interaction between language, training and practice. Therapists' insights and relationships with their different languages shed new light on the complex role of language in therapy. Polyglot therapists also pointed their need for more theoretical attention to questions of language, multilingualism and the therapist. For all these reasons, it would be interesting to see more research exploring this unique situation, that is becoming more frequent and relevant in current times of globalisation, relocation and online therapy.

\section{Acknowledgements}

I would like to thank the anonymous reviewers for their enlightening remarks and suggestions regarding an earlier version of this paper. I am grateful to Doc. PhDr. Miloš Kučera of Charles University, Prague for his academic guidance and helpful comments. To PhD. Adi Ne'eman and PhD. Yaara Fine of Oranim Academic College, Israel and to Asztrik Kovács of Eötvös Loránd University, Budapest for their help and insights regarding methodological issues. To Asko Or-Gordon for his support and invaluable input on the subject. I would also like to thank the participants of this research for sharing their experience and thoughts.

\section{References}

Agha, A. (1994). Honorification. The Annual Review of Anthropology, 23, 277-302.

Amati Mehler, J., Argentieri, S., \& Canestri, J. (1993). The Babel of the unconscious. International Universities Press Inc.

Anzieu, D. (1985). The skin ego. Yale University Press.

Biever, J. L., Castano, M. T., de la Fuentes, C., González, C., Servín-Lopez, S., Sparowls, C., \& Tripp, C. G. (2002). The role of language in training psychologists to work with Hispanic clients. Professional Psychology: Research and Practice, 33, 330-336.

Language and Psychoanalysis, 2021, 10 (1), 4-26.

http://dx.doi.org/10.7565/landp.v10i1.5324 
Braun, V. \& Clarke, V. (2006). Using thematic analysis in psychology. Qualitative Research in Psychology, 3, 77-101.

Buxbaum, E. (1949). The role of second language in the formation of ego and superego. Psychoanalytic Quarterly, 18, 279-289.

Castano, M. T., Biever, J. L., Gonzáles, C. G., \& Anderson, K. B. (2007). Challenges of providing mental health services in Spanish. Professional Psychology: Research and Practice, 38, 667-673.

Clauss, C. S. (1998). Language: The unspoken variable in psychotherapy practice. Psychotherapy: Theory, Research, Practice, Training, 35, 188-196.

Costa, B. (2010). Mother tongue or non-native language? Learning from conversations with bilingual/multilingual therapists about working with clients who do not share their native language. Ethnicity and Inequalities in Health and Social Care, 3, 15-24.

Costa B, Dewaele J.-M. (2012). Psychotherapy across languages: beliefs, attitudes and practices of monolingual and multilingual therapists with their multilingual patients. Language and Psychoanalysis, 1, 18-40.

Dewaele, J.-M. (2004) The emotional force of swearwords and taboo words in the speech of multilinguals. Journal of Multilingual and Multicultural Development, 25, 204-222.

Dewaele, J.-M. (2015). From obscure echo to language of the heart: Multilinguals' language choices for (emotional) inner speech. Journal of Pragmatics, 87, 1-17.

Dewaele, J.-M. (2016). Why do so many bi- and multilinguals feel different when switching languages? International Journal of Multilingualism, 13, 92-105.

De Leersnyder, J., Mesquita, B., \& Kim, H. S. (2011). Where do my emotions belong? A study of immigrants' emotional acculturation. Personality and Social Psychology Bulletin, 37, 451-463.

Dyche, L., \& Zayas, L. H. (1995). The value of curiosity and naiveté for the cross-cultural psychotherapist. Family Process, 34, 389-399.

Ferenczi, S. (1994). On obscene words. In E. Jones (Ed. and Trans.), First contributions to psycho-analysis (pp. 132-153). Routledge. (Oringal work published 1911)

Ferenczi, S. (1985). Hayoman haklini [The clinical diary]. Am Oved. (Oringal work published 1932)

Forrester, J. (1980). Language and the origins of psychoanalysis. Columbia University Press.

Freud, S. (1953). Recommendations to physicians practicing psycho-analysis. In J.

Strachey (Ed. and Trans.) The Standard edition of the complete psychological works

of Sigmund Freud (Volume XII, pp. 109-120). Hogarth Press. (Oringal work published 1912)

Green, A. (2011). Illusions and disillusions of psychoanalytic work. Karnac Books.

Greenson, R. R. (1950). The mother tongue and the mother. International Journal of Psychoanalysis, 31,18-23.

Grosjean, F. (2013). Bilingual and monolingual language modes. In C. A. Chapell (Ed.), The Encyclopedia of applied linguistics. Blackwell Publishing Ltd.

Grosjean, F. (2015). The Complementarity Principle and its impact on processing, acquisition, and dominance. In C. Silva-Corvalán \& J. Treffers-Daller (Ed.), Language dominance in bilinguals: Issues of measurement and operationalization (pp. 66-84). Cambridge University Press.

Gulina, M., \& Dobrolioubova, V. (2018). One language and two mother tongues in the consulting room: Dilemmas of the bilingual psychotherapist. British Journal of Psychotherapy, 34, 3-24.

Hammer, K. (2016). Bilingual bonds: Acculturation, attachment, and being yourself in a new language. International Journal of Language and Culture, 3, 253-279.

Language and Psychoanalysis, 2021, 10 (1), 4-26.

http://dx.doi.org/10.7565/landp.v10i1.5324 
Hollway, W. \& Jefferson, T. (2000). Doing qualitative research differently: free association, narrative and the interview method. Sage.

Jones, E. (1922). Essays in applied psycho-analysis. International Psychoanalytic Press.

Jimanez, J. P. (2004). Between the confusion of tongues and the gift of tongues or working as a psychoanalyst in a foreign language. The International Journal of Psychoanalysis, 85, 1365-1377.

Kramsch, C., \& Gerhards, S. (2012). Im Gespräch: An Interview with Claire Kramsch on the "Multilingual Subject". Die Unterrichtspraxis/Teaching German, 45, 74-82.

Krapf, E. E. (1955). The choice of language in polyglot psychoanalysis. Psychoanalytic Quarterly, 24, 343-357.

Kühne, K., \& Gianelli, C. (2019). Is embodied cognition bilingual? Current evidence and perspectives of the embodied cognition approach to bilingual language processing. Frontiers in Psychology, 10, 1-8.

Lagache, D. (1956). Sur le polyglottisme dans l'analyse [About polyglotism in analysis]. La Psychanalyse, 1, 167-178.

Maxie, A. C., Arnold, D. H., \& Stephenson, M. (2006). Do therapists address ethnic and racial differences in cross-cultural psychotherapy? Psychotherapy: Therapy, Research, Practice, Training, 43, 85-98.

Midgley, N. (2006). Psychoanalysis and qualitative psychology: complementary or contradictory paradigms? Qualitative Research in Psychology, 3, 213-231.

Panicacci, A., \& Dewaele J-M. (2017). "A voice from elsewhere": Migration, personality and multiple selves in multiple languages. International Journal of Multilingualism, 14, 419-436.

Patton, M.Q. (1990). Qualitative evaluation and research methods. Sage.

Pavlenko, A. (2002a). Bilingualism and emotions. Multilingua, 21, 45-78.

Pavlenko, A. (2002b). Emotions and the body in Russian and English. Pragmatics \& Cognition, 10, 207-241.

Pavlenko, A. (2005). Emotions and multilingualism. Cambridge University Press.

Pavlenko, A. (2012). Affective processing in bilingual speakers: Disembodied cognition? International Journal of Psychology, 47, 405-428.

Pedder, J. (1986). Reflections on the theory and practice of supervision. Psychoanalytic Psychotherapy, 2, 1-12.

Schrauf, R., \& Durazo-Arvizu, R. (2006). Bilingual autobiographical memory and emotion: Theory and methods. In A. Pavlenko (Ed.), Bilingual minds: Emotional experience, expression and representation (pp. 284-311). Multilingual Matters Ltd.

Stahl Freedman, R. (2017). Cross-cultural treatment issues in psychoanalysis. Language and Psychoanalysis, 6, 66-98.

Stern, D. N. (1998). The interpersonal world of the infant: A view from psychoanalysis and developmental psychology. Routledge.

Szekacs-Weisz, J. (2005). How to be a bi-lingual psychoanalyst. In J. Szekacs-Weisz \& I. Ward (Ed.), Lost childhood and the language of exile (pp.21-28). Imago East West.

Verdinelli, S., \& Biever, J. L. (2009). Spanish-English bilingual psychotherapists: Personal and professional language development and use. Cultural Diversity and Ethnic Psychology, 15, 230-242.

Walsh, S. D. (2014). The bilingual therapist and transference to language: Language use in therapy and its relationship to object relational context. Psychoanalytic Dialogues, 42, 56-71.

Whorf, B. L. (1956). Language, thought and reality. In B. Carroll (Ed.), Selected writings of Benjamin Lee Whorf (pp. 315-344). MIT Press.

Language and Psychoanalysis, 2021, 10 (1), 4-26.

http://dx.doi.org/10.7565/landp.v10i1.5324 
Winnicott, D. W. (1953). Transitional objects and transitional phenomena - A study of the first not-me possessions. International Journal of Psychoanalysis, 34, 89-97.

Winnicott, D. W. (1960). The theory of the parent-infant relationship. International Journal of Psychoanalysis, 41, 585-595.

Winnicott, D. W. (1971). Playing and reality. Basic Books.

\section{Appendix: Participants*}

\begin{tabular}{|c|c|c|c|c|c|c|c|c|}
\hline Name & Title & $\begin{array}{l}\text { Professional } \\
\text { orientation }\end{array}$ & $\begin{array}{l}\text { Language in } \\
\text { therapy** }\end{array}$ & $\begin{array}{l}\text { Mother } \\
\text { tongue }\end{array}$ & $\begin{array}{l}\text { Current } \\
\text { residence } \\
\text { and status } \\
\end{array}$ & Age & $\begin{array}{l}\text { Other } \\
\text { languages }\end{array}$ & $\begin{array}{l}\text { Place of } \\
\text { major } \\
\text { training }\end{array}$ \\
\hline Pavel & psychologist & Psychodynamic & $\begin{array}{l}\text { Czech } \\
\text { Italian }\end{array}$ & Czech & $\mathrm{CR}$ & 35 & $\begin{array}{l}\text { English } \\
\text { German }\end{array}$ & $\mathrm{CR}$ \\
\hline Luciana & $\begin{array}{l}\text { psychoanalyst, } \\
\text { supervisor }\end{array}$ & $\begin{array}{l}\text { Lacanian } \\
\text { psychoanalytic }\end{array}$ & $\begin{array}{l}\text { Hebrew } \\
\text { Spanish }\end{array}$ & Spanish & $\begin{array}{l}\text { Israel, } \\
\text { Immigrant } \\
(40)^{* * *}\end{array}$ & 57 & English & Paraguay \\
\hline David & psychologist & psychodynamic & $\begin{array}{l}\text { English } \\
\text { Hebrew } \\
\text { Czech } \\
\text { German }\end{array}$ & Hebrew & $\begin{array}{l}\mathrm{CR} \text {, } \\
\text { Immigrant } \\
(30)\end{array}$ & 55 & Arabic & $\mathrm{CR}$ \\
\hline George & $\begin{array}{l}\text { Psychologist in } \\
\text { internship }\end{array}$ & psychodynamic & $\begin{array}{l}\text { Hebrew } \\
\text { Arabic }\end{array}$ & Arabic & Israel & 35 & English & Israel \\
\hline Alina & Music therapist & $\begin{array}{l}\text { Lacanian } \\
\text { psychoanalytic }\end{array}$ & $\begin{array}{l}\text { Hebrew } \\
\text { Russian }\end{array}$ & Russian & $\begin{array}{l}\text { Israel, } \\
\text { Immigrant } \\
\text { (19) }\end{array}$ & 55 & English & Israel \\
\hline Inbal & $\begin{array}{l}\text { psychologist, } \\
\text { supervisor }\end{array}$ & Psychodynamic & $\begin{array}{l}\text { Hebrew } \\
\text { Spanish } \\
\text { Portuguese }\end{array}$ & Portuguese & $\begin{array}{l}\text { Israel, } \\
\text { Immigrant } \\
\text { (22) }\end{array}$ & 50 & English & Israel \\
\hline Edith & psychologist & Psychodynamic & $\begin{array}{l}\text { English } \\
\text { Hungarian } \\
\text { Hebrew }\end{array}$ & Hungarian & Hungary & 35 & $\begin{array}{l}\text { French } \\
\text { Czech }\end{array}$ & Hungary \\
\hline Joel & $\begin{array}{l}\text { psychologist, } \\
\text { supervisor, }\end{array}$ & Psychodynamic & $\begin{array}{l}\text { Hebrew } \\
\text { English } \\
\text { French } \\
\text { German }\end{array}$ & French & $\begin{array}{l}\text { Israel, } \\
\text { Immigrant } \\
(24)\end{array}$ & 75 & & Canada \\
\hline Antonella & psychologist & $\begin{array}{l}\text { CBT and } \\
\text { Interpersonal } \\
\text { psychotherapy }\end{array}$ & $\begin{array}{l}\text { Italian } \\
\text { French } \\
\text { English }\end{array}$ & $\begin{array}{l}\text { Italian } \\
\text { French }\end{array}$ & $\begin{array}{l}\text { Slovakia } \\
\text { (temporary) }\end{array}$ & 50 & & Italy \\
\hline
\end{tabular}

* Names and identifying details have been changed.

** Languages in therapy are presented according to frequency of use, from the most frequent to the least frequent.

$* * *$ Number in parenthesis represents the age at immigration. 